\title{
Usage of Fuzzy Multi-criteria Decision Making Method to Solve the Automobile Selection Problem
}

\author{
Aytac YILDIZ* \\ Department of Automotive Engineering, Faculty of Technology, Amasya University, Amasya, \\ Turkey
}

\author{
Engin Ufuk ERGUL \\ Department of Electrical and Electronics Engineering, Faculty of Technology, Amasya \\ University, Amasya, Turkey
}

\begin{tabular}{|c|c|}
\hline Article history & Depending on today's emerging technology, manufacturers produce \\
\hline $\begin{array}{l}\text { Received: } \\
28.10 .2014\end{array}$ & $\begin{array}{l}\text { various automobile models. It is a complicated situation to select } \\
\text { the best automobile from various brands and models. It is difficult }\end{array}$ \\
\hline $\begin{array}{l}\text { Received in revised form: } \\
27.11 .2014\end{array}$ & $\begin{array}{l}\text { to select an automobile by using many criteria. Using multi-criteria } \\
\text { decision making methods in the solution of many problems such as }\end{array}$ \\
\hline $\begin{array}{l}\text { Accepted: } \\
01.12 .2014\end{array}$ & $\begin{array}{l}\text { the automobile selection which has many criteria eliminates the } \\
\text { complexity and contributes to the solution of the problem. Fuzzy }\end{array}$ \\
\hline Key words: & $\begin{array}{l}\text { TOPSIS method is used to obtain the best result in a decision } \\
\text { problem. }\end{array}$ \\
\hline $\begin{array}{l}\text { automobile selection; multi- } \\
\text { criteria decision making; fuzzy }\end{array}$ & \\
\hline TOPSIS & $\begin{array}{l}\text { In this study, fuzzy TOPSIS method is used to solve the best } \\
\text { automobile selection problem of a person who plans to buy an } \\
\text { automobile from three alternative automobiles in the same segment. } \\
\text { The criteria of the best automobile selection problem are } \\
\text { determined by searching the literature and by considering the } \\
\text { opinions of the person who plans to buy the automobile. The } \\
\text { alternative automobiles are evaluated by three experts, and the best } \\
\text { automobile is selected by using the fuzzy TOPSIS method. }\end{array}$ \\
\hline
\end{tabular}

\footnotetext{
* Correspondence: aytac.yildiz@amasya.edu.tr
} 


\section{Introduction}

Many problems encountered in daily life have multiple criteria. Therefore, people are forced to solve these problems. Thus, multicriteria decision-making methods (MCDMs) are applied to solve these problems. MCDMs help us to find the best alternative. Some of MCDMs are Techniques for Order Preference by Similarity to Ideal Solution (TOPSIS), Analytic Network Process (ANP), Fuzzy ANP (FANP), Analytic Hierarchy Process (AHP), ELECTRE, Data Envelopment Analysis (DEA), PROMETHEE etc. Some useful information about these methods can be found in [1].

MCDM methods can be divided into three group as deterministic, stochastic and fuzzy. It is the state of that on the basis of fuzzy logic and fuzzy set theory and is one of the strongest tools to solve decision making problems [2].

Automobile industry changes very rapidly and offers various brands and models. As a result, it affects the decision-making process of customers. So, automobile purchasing process must be thought a MCDM problem and MCDM methods must be used to solve it.

Bhyun [3] used AHP for deciding on automobile purchase. Yayla and Yildiz [2] used fuzzy ANP method in automobile purchasing decision making and selected the best automobile from three alternatives in the same segment. Yousefi and Hadi-Vencheh [4] proposed an integrated model from AHP and TOPSIS to examine Iran automobile industry. Also, they applied DEA method for comparing the results of these two methods. Gungor and Isler [5] used AHP method to solve the automobile purchasing problem. Terzi et al.[6] applied AHP method and goal programming together to solve the automobile selection by considering the effects of customer and the seller together. Balli et al. [7] used PROMETHEE method to select the best automobile from seven different brands. Apak et al. [8] used AHP for determining to consumer preferences of luxury car features.

In this study, fuzzy TOPSIS method is used in the decision making process of automobile purchasing. Customers consider a lot of criteria before buying an automobile. Main purpose of this study is to select the best alternative automobile according to the criteria. In this study, the criteria are determined as: engine power, fuel consumption, after-sales service, cylinder volume, sale price, aesthetic and comfort.

This paper is arranged as follows. In Section 2, the fuzzy TOPSIS method is presented. Fuzzy TOPSIS method is applied to the best automobile selection problem and the results are given in Section 3. Overall conclusions and future works are discussed in Section 4.

\section{The Fuzzy TOPSIS method}

The TOPSIS method is generally used for ranking the real life decision making problems. The major disadvantage of the TOPSIS method fail to capture uncertainty in the decision making process. To eliminate this disadvantage, the fuzzy set theory is applied to TOPSIS method. Therefore, the fuzzy TOPSIS method is more powerful than traditional TOPSIS method [9].

Fuzzy TOPSIS method is generalization of TOPSIS on fuzzy atmosphere. TOPSIS method suggested by Hwang and Yoon [10] was a famous MCDM method [11]. The idea behind TOPSIS method is to identify the positive ideal solution (PIS) and negative ideal solution (NIS) and then alternatives are determined based on the distance from the ideal solutions. It is determine a closeness index depending on the distance to PIS and to NIS. Then, it selects best alternative according to the maximum closeness index. In fuzzy TOPSIS method, the ratings and the weights are defined by the linguistic variables which are called triangular fuzzy numbers (TFN) [9].

In the fuzzy TOPSIS method, fuzzy positive ideal solution (FPIS) and fuzzy negative ideal solution (FNIS) are computed by considering the weight of criteria. Then, the closeness index of each alternative is computed, and the alternatives are ranked [2].

TOPSIS method was extended by Chen [12] to fuzzy atmosphere [13]. In the fuzzy TOPSIS method, the fuzzy importance weights of criteria $\left(\tilde{w}_{j} ; j=1,2, \ldots\right.$, number of criteria $\left.(n)\right)$ and the fuzzy rating of alternatives at criteria ( $\tilde{x}_{i j}, i=1,2, \ldots$, numbe of alternative $(m)$,

$j=1,2, \ldots$, numberof criteria $(n))$ are inputs and 
put into place in matrix form. The steps of fuzzy TOPSIS algorithm are given below [14].

Step 1: Construct the fuzzy decision matrix for the alternatives and the criteria.

$$
\begin{aligned}
& \widetilde{D}=\left[\begin{array}{cccc}
\tilde{x}_{11} & \tilde{x}_{12} & \cdots & \tilde{x}_{2 n} \\
\tilde{x}_{21} & \tilde{x}_{22} & \cdots & \tilde{x}_{2 n} \\
\vdots & \vdots & \ddots & \vdots \\
\tilde{x}_{m 1} & \tilde{x}_{m 2} & \cdots & \tilde{x}_{m m}
\end{array}\right] \\
& \tilde{\mathrm{W}}=\left[\tilde{u}_{1}, \tilde{u}_{2}, \cdots, \tilde{x}_{n}\right]
\end{aligned}
$$

Step 2: Compute the normalized fuzzy decision matrix, $\widetilde{R}$ :

$$
\begin{aligned}
& \widetilde{R}=\left\lfloor\tilde{r}_{i j}\right\rfloor_{m a n} \quad i=1,2, \ldots, m, \quad j=1,2, \ldots, n \\
& \tilde{r}_{i j}=\left(\frac{l_{i j}}{u_{j}^{+}}, \frac{m_{i j}}{u_{j}^{+}}, \frac{u_{i j}}{u_{j}^{+}}\right) \quad \text { (Benefit crite }
\end{aligned}
$$

where;

$$
\begin{aligned}
& u_{j}^{+}=\max _{i} u_{i j} \\
& \tilde{r}_{i j}=\left(\frac{l_{i}^{-}}{u_{i j}}, \frac{l_{i}^{-}}{m_{i j}}, \frac{l_{i}^{-}}{l_{i j}}\right)
\end{aligned}
$$

where;

$$
l_{j}^{-}=\min _{i} l_{i j}
$$

Step 3: Compute the weighted normalized fuzzy decision matrix is, $\tilde{\mathrm{V}}$ :

$$
\widetilde{\mathrm{V}}=\left|\tilde{v}_{i j}\right|_{m \times n}, i=1,2, \ldots, m, \quad j=1,2, \ldots, n
$$

$\tilde{v}_{i j}$ (The weighted normalized fuzzy value) is computed as:

$$
\tilde{v}_{i j}=\widetilde{r}_{i j} \otimes \widetilde{w}_{j}, i=1,2, \ldots, m, \quad j=1,2, \ldots, n
$$

Step 4: Compute FPIS and FNIS of the alternatives as:

$$
\begin{aligned}
& A^{+}=\left\{\tilde{v}_{1}^{+}, \tilde{v}_{2}^{+}, \ldots, \tilde{v}_{n}^{+}\right\} \\
& A^{-}=\left\{\tilde{v}_{1}^{-}, \tilde{v}_{2}^{-}, \ldots, \tilde{v}_{n}^{-}\right\}
\end{aligned}
$$

Where $\tilde{v}_{j}^{+}=(1,1,1)$ and $\tilde{v}_{j}^{-}=(0,0,0), j=1,2, \ldots, n$. 
Step 5: Compute the distance of each alternative from FPIS and FNIS.

$$
\begin{aligned}
& \mathrm{d}_{i}^{+}=\sum_{j=1}^{n} \mathrm{~d}\left(\tilde{v}_{i j}-\tilde{v}_{j}^{+}\right), i=1,2, \ldots, m ; j=1,2, \ldots, n \\
& \mathrm{~d}_{i}^{-}=\sum_{j=1}^{n} \mathrm{~d}\left(\tilde{v}_{i j}-\tilde{v}_{j}^{-}\right), i=1,2, \ldots, m ; j=1,2, \ldots, n
\end{aligned}
$$

Step 6: Compute the closeness index $\left(\mathrm{C}_{\mathrm{i}}\right)$ of each alternative as follows:

$$
\mathrm{C}_{i}=\mathrm{d}_{i}^{-} /\left(\mathrm{d}_{i}^{-}+\mathrm{d}_{i}^{*}\right), \quad i=1,2, \ldots, m
$$

Step 7: Alternatives are ranked in respect of the closeness index.

\section{Selection of the best automobile}

In this study, fuzzy TOPSIS method is used to solve the best automobile selection problem of a person who plans to buy an automobile from three alternative automobiles in the same segment. All automobiles have automatic transmission and they use gasoline. Firstly, the criteria of the best automobile selection problem are determined by searching the literature and by considering the opinions of the person who plans to buy the automobile. According to the obtained information, the criteria are determined as: engine power, fuel consumption, after-sales service, cylinder volume, sale price, aesthetic and comfort. Hierarchy of the automobile selection problem is represented in Figure 1.

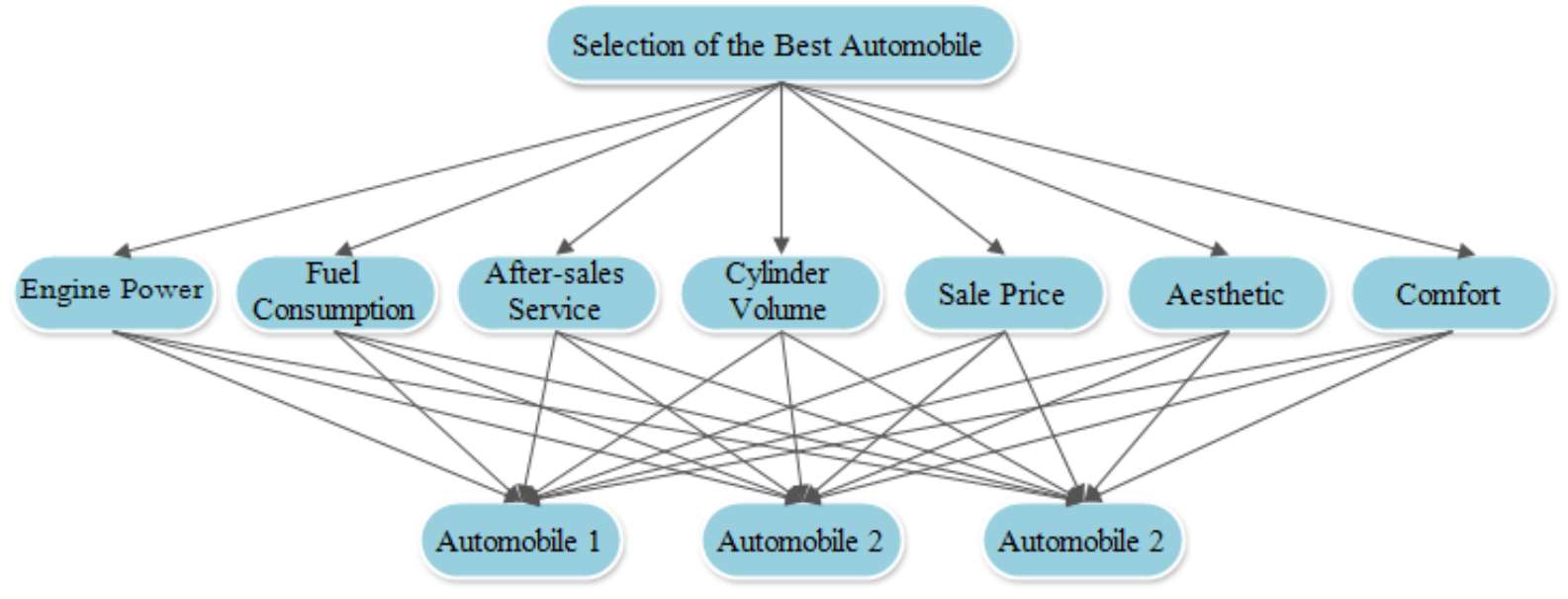

Figure1. Hierarchy of the best automobile selection problem.

A team of three decision makers (DM1, DM2, DM3) consisting of two lecturers from the department of Automotive Technology of Vocational School of Amasya University and the person who plans to buy the automobile is created to evaluate the alternatives according to Figure 1 . The team evaluates the alternatives by taking in the consideration of the catalogue information of the automobiles. In the first step of the evaluation, each decision maker evaluates the criteria like in Table 2 according to the linguistic variables in Table 1 to define the importance weights of each criterion. 
Table 1. Linguistic variables used to express the weight importance of the criteria [12].

\begin{tabular}{lc} 
Linguistic variable & Triangular Fuzzy Numbers (TFNs) \\
\hline Very low (VL) & $(0,0,0.1)$ \\
Low (L) & $(0,0.1,0.3)$ \\
Medium low (ML) & $(0.1,0.3,0.5)$ \\
Medium (M) & $(0.3,0.5,0.7)$ \\
Medium high (MH) & $(0.5,0.7,0.9)$ \\
High (H) & $(0.7,0.9,1)$ \\
Very high (VH) & $(0.9,1,1)$ \\
\hline
\end{tabular}

Table 2. Evaluations of the decision team according to the determined criteria.

\begin{tabular}{lccc}
\hline \multirow{2}{*}{ Automobile Selection Criteria } & \multicolumn{3}{c}{ Decision Makers } \\
\cline { 2 - 4 } & DMl & DM2 & DM3 \\
\hline Engine Power & $\mathrm{H}$ & $\mathrm{H}$ & $\mathrm{VH}$ \\
Fuel Consumption & $\mathrm{VH}$ & $\mathrm{VH}$ & $\mathrm{VH}$ \\
After-sales Service & $\mathrm{VH}$ & $\mathrm{VH}$ & $\mathrm{H}$ \\
Cylinder Volume & $\mathrm{H}$ & $\mathrm{H}$ & $\mathrm{MH}$ \\
Sale Price & $\mathrm{VH}$ & $\mathrm{VH}$ & $\mathrm{VH}$ \\
Aesthetic & $\mathrm{H}$ & $\mathrm{VH}$ & $\mathrm{H}$ \\
Comfort & $\mathrm{H}$ & $\mathrm{VH}$ & $\mathrm{VH}$ \\
\hline
\end{tabular}

In the next step, the alternative automobiles are by considering the linguistic variables in Table 3 . evaluated by decision makers as given in Table 4

Table 3. Linguistic variables used in the evaluation of the alternatives [12]

\begin{tabular}{lc}
\hline Linguistic Variables & Triangular Fuzzy Numbers (TFNs) \\
\hline Very poor (VP) & $(0,0,1)$ \\
Poor (P) & $(0,1,3)$ \\
Medium poor (MP) & $(1,3,5)$ \\
Fair (F) & $(3,5,7)$ \\
Medium good (MG) & $(5,7,9)$ \\
Good (G) & $(7,9,10)$ \\
Very good (VG) & $(9,10,10)$ \\
\hline
\end{tabular}


Table 4. Evaluations of the alternatives according to the selection criteria.

\begin{tabular}{|c|c|c|c|c|}
\hline \multirow{2}{*}{$\begin{array}{c}\text { Automobile Selection } \\
\text { Criteria }\end{array}$} & \multirow{2}{*}{ Alternatives } & \multicolumn{3}{|c|}{ Decision Makers } \\
\hline & & DMl & DM2 & DM3 \\
\hline \multirow{3}{*}{ Engine Power } & Automobile 1 & MG & MG & $F$ \\
\hline & Automobile 2 & $\mathrm{G}$ & $\mathrm{G}$ & VG \\
\hline & Automobile 3 & $\mathrm{G}$ & $\mathrm{G}$ & VG \\
\hline \multirow{3}{*}{ Fuel Consumption } & Automobile 1 & MG & $\mathrm{G}$ & MG \\
\hline & Automobile 2 & $\mathrm{G}$ & VG & VG \\
\hline & Automobile 3 & $\mathrm{~F}$ & $\mathrm{MG}$ & $\mathrm{F}$ \\
\hline \multirow{3}{*}{ After-sales Service } & Automobile 1 & VG & $\mathrm{G}$ & VG \\
\hline & Automobile 2 & $\mathrm{G}$ & VG & MG \\
\hline & Automobile 3 & $\mathrm{G}$ & MG & MG \\
\hline \multirow{3}{*}{ Cylinder Volume } & Automobile 1 & MG & $\mathrm{G}$ & VG \\
\hline & Automobile 2 & MG & $\mathrm{G}$ & $\mathrm{G}$ \\
\hline & Automobile 3 & $\mathrm{G}$ & MG & MG \\
\hline \multirow{3}{*}{ Sale Price } & Automobile 1 & $\mathrm{~F}$ & $\mathrm{G}$ & $\mathrm{F}$ \\
\hline & Automobile 2 & $\mathrm{G}$ & VG & VG \\
\hline & Automobile 3 & MG & MG & MG \\
\hline \multirow{3}{*}{ Aesthetic } & Automobile 1 & VG & $\mathrm{G}$ & VG \\
\hline & Automobile 2 & $\mathrm{G}$ & VG & MG \\
\hline & Automobile 3 & MG & MG & $\mathrm{F}$ \\
\hline \multirow{3}{*}{ Comfort } & Automobile 1 & $\mathrm{VG}$ & $\mathrm{G}$ & VG \\
\hline & Automobile 2 & $\mathrm{G}$ & VG & $\mathrm{G}$ \\
\hline & Automobile 3 & $\mathrm{G}$ & MG & $\mathrm{G}$ \\
\hline
\end{tabular}

The linguistic evaluations in Table 2 and Table 4 TFNs given in Table 5 and Table 6. formed by decision makers are converting to

Table 5. Convert to triangular fuzzy number of linguistic evaluation results of criteria.

\begin{tabular}{lccc}
\hline \multirow{2}{*}{$\begin{array}{c}\text { Automobile Selection } \\
\text { Criteria }\end{array}$} & \multicolumn{3}{c}{ Decision Makers } \\
\cline { 2 - 4 } & DM1 & DM2 & DM3 \\
\hline Engine Power & $(0.7,0.9,1)$ & $(0.7,0.9,1)$ & $(0.9,1,1)$ \\
Fuel Consumption & $(0.9,1,1)$ & $(0.9,1,1)$ & $(0.9,1,1)$ \\
After-sales Service & $(0.9,1,1)$ & $(0.9,1,1)$ & $(0.7,0.9,1)$ \\
Cylinder Volume & $(0.7,0.9,1)$ & $(0.7,0.9,1)$ & $(0.5,0.7,0.9)$ \\
Sale Price & $(0.9,1,1)$ & $(0.9,1,1)$ & $(0.9,1,1)$ \\
Aesthetic & $(0.7,0.9,1)$ & $(0.9,1,1)$ & $(0.7,0.9,1)$ \\
Comfort & $(0.7,0.9,1)$ & $(0.9,1,1)$ & $(0.9,1,1)$ \\
\hline
\end{tabular}


Table 6. Convert to triangular fuzzy number of linguistic evaluation results of alternatives.

\begin{tabular}{ccccc}
\hline \multirow{2}{*}{$\begin{array}{c}\text { Automobile Selection } \\
\text { Criteria }\end{array}$} & \multirow{2}{*}{ Alternatives } & \multicolumn{3}{c}{ Decision Makers } \\
\cline { 3 - 5 } Engine Power & Automobile 1 & $(5,7,9)$ & $(5,7,9)$ & $(3,5,7)$ \\
& Automobile 2 & $(7,9,10)$ & $(7,9,10)$ & $(9,10,10)$ \\
& Automobile 3 & $(7,9,10)$ & $(7,9,10)$ & $(9,10,10)$ \\
\hline \multirow{3}{*}{ Fuel Consumption } & Automobile 1 & $(5,7,9)$ & $(7,9,10)$ & $(5,7,9)$ \\
& Automobile 2 & $(7,9,10)$ & $(9,10,10)$ & $(9,10,10)$ \\
& Automobile 3 & $(3,5,7)$ & $(5,7,9)$ & $(3,5,7)$ \\
\hline \multirow{3}{*}{ After-sales Service } & Automobile 1 & $(9,10,10)$ & $(7,9,10)$ & $(9,10,10)$ \\
& Automobile 2 & $(7,9,10)$ & $(9,10,10)$ & $(5,7,9)$ \\
& Automobile 3 & $(7,9,10)$ & $(5,7,9)$ & $(5,7,9)$ \\
\hline \multirow{3}{*}{ Cylinder Volume } & Automobile 1 & $(5,7,9)$ & $(7,9,10)$ & $(9,10,10)$ \\
& Automobile 2 & $(5,7,9)$ & $(7,9,10)$ & $(7,9,10)$ \\
& Automobile 3 & $(7,9,10)$ & $(5,7,9)$ & $(5,7,9)$ \\
\hline \multirow{3}{*}{ Sale Price } & Automobile 1 & $(3,5,7)$ & $(7,9,10)$ & $(3,5,7)$ \\
& Automobile 2 & $(7,9,10)$ & $(9,10,10)$ & $(9,10,10)$ \\
& Automobile 3 & $(5,7,9)$ & $(5,7,9)$ & $(5,7,9)$ \\
\hline \multirow{2}{*}{ Aesthetic } & Automobile 1 & $(9,10,10)$ & $(7,9,10)$ & $(9,10,10)$ \\
& Automobile 2 & $(7,9,10)$ & $(9,10,10)$ & $(5,7,9)$ \\
& Automobile 3 & $(5,7,9)$ & $(5,7,9)$ & $(3,5,7)$ \\
\hline \multirow{2}{*}{ Comfort } & Automobile 1 & $(9,10,10)$ & $(7,9,10)$ & $(9,10,10)$ \\
& Automobile 2 & $(7,9,10)$ & $(9,10,10)$ & $(7,9,10)$ \\
& Automobile 3 & $(7,9,10)$ & $(5,7,9)$ & $(7,9,10)$ \\
\hline
\end{tabular}

The importance weights of seven criteria in Table evaluations of the three decision makers. 7 are computed by taking the average of the

Table 7. Importance weight of the automobile selection criteria

\begin{tabular}{lc}
\hline \multicolumn{1}{c}{$\begin{array}{c}\text { Automobile Selection } \\
\text { Criteria }\end{array}$} & Importance Weights \\
\hline Engine Power & $(0.767,0.933,1)$ \\
Fuel Consumption & $(0.9,1,1)$ \\
After-sales Service & $(0.833,0.967,1)$ \\
Cylinder Volume & $(0.633,0.833,0.967)$ \\
Sale Price & $(0.9,1,1)$ \\
Aesthetic & $(0.767,0.933,1)$ \\
Comfort & $(0.833,0.967,1)$ \\
\hline
\end{tabular}

Fuzzy decision matrix given in the Table 8 is normalized by applying Eq.4 and normalized fuzzy decision matrix is obtained as Table 9. 
Table 8. Fuzzy decision matrix of the automobile selection problem.

\begin{tabular}{lccc}
\hline $\begin{array}{c}\text { Automobile Selection } \\
\text { Criteria }\end{array}$ & Automobile 1 & Automobile 2 & Automobile 3 \\
\hline Engine Power & $(4.333,6.333,8.333)$ & $(7.667,9.333,10)$ & $(7.667,9.333,10)$ \\
Fuel Consumption & $(5.667,7.667,9.333)$ & $(8.333,9.667,10)$ & $(3.667,5.667,7.667)$ \\
After-sales Service & $(8.333,9.667,10)$ & $(7,8.667,9.667)$ & $(5.667,7.667,9.333)$ \\
Cylinder Volume & $(7,8.667,9.667)$ & $(6.333,8.333,9.667)$ & $(5.667,7.667,9.333)$ \\
Sale Price & $(4.333,6.333,8)$ & $(8.333,9.667,10)$ & $(5,7,9)$ \\
Aesthetic & $(8.333,9.667,10)$ & $(7,8.667,9.667)$ & $(4.333,6.333,8.333)$ \\
Comfort & $(8.333,9.667,10)$ & $(7.667,9.333,10)$ & $(6.333,8.333,9.667)$ \\
\hline
\end{tabular}

Table 9. Normalized fuzzy decision matrix of the automobile selection problem.

\begin{tabular}{lccc}
\hline \multicolumn{1}{c}{$\begin{array}{c}\text { Automobile Selection } \\
\text { Criteria }\end{array}$} & Automobile 1 & Automobile 2 & Automobile 3 \\
\hline Engine Power & $(0.433,0.633,0.833)$ & $(0.767,0.933,1)$ & $(0.767,0.933,1)$ \\
Fuel Consumption & $(0.567,0.767,0.933)$ & $(0.833,0.967,1)$ & $(0.367,0.567,0.767)$ \\
After-sales Service & $(0.833,0.967,1)$ & $(0.7,0.867,0.967)$ & $(0.567,0.767,0.933)$ \\
Cylinder Volume & $(0.724,0.897,1)$ & $(0.655,0.862,1)$ & $(0.586,0.793,0.966)$ \\
Sale Price & $(0.433,0.633,0.8)$ & $(0.833,0.967,1)$ & $(0.5,0.7,0.9)$ \\
Aesthetic & $(0.833,0.967,1)$ & $(0.7,0.867,0.967)$ & $(0.433,0.633,0.833)$ \\
Comfort & $(0.833,0.967,1)$ & $(0.767,0.933,1)$ & $(0.633,0.833,0.967)$ \\
\hline
\end{tabular}

Each value in the normalized fuzzy decision criterion and weighted normalized fuzzy decision matrix is multiplied with the related weight of matrix given in the Table 10 is obtained.

Table 10. Weighted normalized fuzzy decision matrix of the automobile selection problem.

\begin{tabular}{lccc}
\hline $\begin{array}{c}\text { Automobile Selection } \\
\text { Criteria }\end{array}$ & Automobile 1 & Automobile 2 & Automobile 3 \\
\hline Engine Power & $(0.332,0.591,0.833)$ & $(0.588,0.871,1)$ & $(0.588,0.871,1)$ \\
Fuel Consumption & $(0.51,0.767,0.933)$ & $(0.75,0.967,1)$ & $(0.33,0.567,0.767)$ \\
After-sales Service & $(0.694,0.934,1)$ & $(0.583,0.838,0.967)$ & $(0.472,0.741,0.933)$ \\
Cylinder Volume & $(0.459,0.747,0.967)$ & $(0.415,0.718,0.967)$ & $(0.371,0.661,0.933)$ \\
Sale Price & $(0.39,0.633,0.8)$ & $(0.75,0.967,1)$ & $(0.45,0.7,0.9)$ \\
Aesthetic & $(0.639,0.902,1)$ & $(0.537,0.809,0.967)$ & $(0.332,0.591,0.833)$ \\
Comfort & $(0.694,0.934,1)$ & $(0.639,0.902,1)$ & $(0.528,0.806,0.967)$ \\
\hline
\end{tabular}

Distance from FPIS $\left(d_{i}^{+}\right)$values of alternative automobiles are computed by using Eq.10 and their distance from FNIS $\left(d_{i}^{-}\right)$values are computed by using Eq.11. Then, closeness index
$\left(C_{i}\right)$ is computed for each alternative automobile by using Eq.14. These values are given in Table 11 . 
Table 11. $d_{i}^{+}, d_{i}{ }^{-}$and $C_{i}$ values.

\begin{tabular}{cccc}
\hline & Automobile 1 & Automobile 2 & Automobile 3 \\
\hline$d^{+}$ & 2,127 & 1,681 & 2,609 \\
$d_{i}^{-}$ & 5,394 & 5,861 & 4,970 \\
$C_{i}$ & 0,717 & 0,777 & 0,656 \\
\hline
\end{tabular}

According to closeness index values of alternatives in Table 11, alternative automobiles are ranked as Automobile $2>$ Automobile $1>$ Automobile 3 from the most convenient to the least appropriate. According to this result, Automobile 2 will be convenient for people who plan to buy an automobile to select "Automobile 2 ", because it has the highest closeness index.

\section{Conclusions}

To buy a new automobile is a very difficult process in terms of choosing among the alternative automobiles beside the difficulty of finding the necessary funding. Because, people do not look at only one criteria when buying an automobile. Automobiles become very technological in parallel to today's developing technology. Depending on the change of the consumer perspectives in 1960s, now consumers want automobiles which have low price, good performance, advanced technical features and comfort. Therefore, the process of buying an automobile is transformed into the problem of buying an automobile.

In this paper, fuzzy TOPSIS method is used as a MCDM. Fuzzy TOPSIS method considers a number of criteria and ranks the alternatives by computing the distance from the ideal solution. In the evaluation stage of the selection regarding multi-criteria, it is faced with some problems such as; determination of the importance weights and some conflicts between criteria. Decisionmakers must make the decision making process by using the correct methods to solve such problems. Therefore, it is very important to use MCDMs that can evaluate many qualitative and quantitative criteria together during the decision making process.

According to the results obtained from the study, it will be appropriate for people who plan to buy an automobile to select "Automobile 2", because it has the highest closeness index. Accordingly,
"Automobile 2" is selected; an automobile that is more powerful, more comfortable, more aesthetic, less fuel consumption and after-sales services will be purchased.

The fuzzy TOPSIS method used in the study makes easier to solve the decision making problem by getting the opinions of the decision makers when there is uncertainty in decision making process. In future works, Interval Type-2 fuzzy sets, fuzzy ANP and Choquet Integral methods will be used to solve this problem and the results will be compared with this study.

\section{References}

[1] Ishizaka A, Nemery P. Multi-Criteria Decision Analysis: Methods and Software. Wiley, 2013.

[2] Yayla A.Y, Yildiz A. Fuzzy ANP based MCDM methodology for a family automobile purchasing decision. South African Journal of Industrial Engineering 2013, 24(2): 167-180.

[3] Bhyun D.H. The AHP approach for selecting an automobile purchase model. Information and Management 2001; 38: 289-297.

[4] Yousefi A, Hadi-Vencheh A. An integrated group decision making model and its evaluation by DEA for automobile industry. Expert Systems with Applications 2010; 37(2): 8542-8556.

[5] Gungor I, Isler D.B. Automobile selection with analytic hierarchy process approach. Zonguldak Kara Elmas University, Journal of Social Sciences 2005; 1(2): 21-33.

[6] Terzi U, Hacaloglu S.E, Aladag Z. A decision support model for the automobile purchasing problem. Istanbul Ticaret University Journal of Science 2006; 5(10): 43-49.

[7] Balli S, Karasulu B, Korukoglu S. An application of fuzzy promethee method for 
selecting optimal car problem. Dokuz Eylul University Journal of Faculty of Economics and Administrative Sciences 2007; 22(1): 139-147.

[8] Apak S, Gogus G.G., Karakadilar I.S. An analytic hierarchy process approach with a novel framework for luxury car selection. Procedia-Social and Behavioral Sciences 2012; 58: 1301-1308.

[9] Kannan D, Jabbour A.B.L.S, Jabbour C.J.C. Selecting green suppliers based on GSCM practices: Using fuzzy TOPSIS applied to a Brazilian electronics company. European Journal of Operational Research 2014; 233: 432-447.

[10] Hwang C.L, Yoon K. Multiple Attribute Decision Making: Methods and Applications. Springer-Verlag, New York, 1981.

[11] Wang, Y-J. The evaluation of financial performance for Taiwan container shipping companies by fuzzy TOPSIS. Applied Soft Computing 2014; 22: 28-35.

[12] Chen C.T. Extensions of the TOPSIS for group decision-making under fuzzy environment. Fuzzy Sets and Systems 2000; 114: 1-9.

[13] Wang J, Cheng C, Huang K. Fuzzy hierarchical TOPSIS for supplier selection. Applied Soft Computing 2009; 9(1): 377-386.

[14] Boran F.E, Genc S, Kurt M, Akay D. A multi-criteria intuitionistic fuzzy group decision making for supplier selection with TOPSIS method. Expert Systems with Applications 2009; 36(8): 11363- 11368. 